\title{
Secondary School Mathematics Teachers' Attitude in Teaching Mathematics
}

\author{
Mulugeta Atnafu \\ Addis Ababa University, Addis Ababa, Ethiopia
}

\begin{abstract}
The purpose of this study was to examine Addis Ababa secondary school mathematics teachers' attitude in teaching mathematics. 148 mathematics teachers were selected using cluster sampling from Addis Ababa administration region. The study used survey method of data collection and it includes both quantitative and qualitative research methods. From the independent t-test, ANOVA, tukey test and regression analysis, some of the results obtained were: the majority of the secondary school mathematics teachers do not possess positive attitude in teaching mathematics; the most challenge area that affect the attitude in teaching mathematics was motivation in teaching mathematics; no significant differences in all variables with respect to sex and service year; the medium age of mathematics teachers were found to have significantly the most successful in teaching mathematics than young and old mathematics teachers; the master mathematics teachers were found to have significantly the highest and the diploma mathematics teachers were found to have the least attitude, confidence and anxiety of teaching mathematics; the relatively high salary of the mathematics teachers were found to have significantly the highest attitude in teaching mathematics and the average salary of the mathematics teachers were found to have significantly the highest anxiety in teaching mathematics. All the variables sex, age, education, service year and salary of the mathematics teachers were significantly contributing to the equation for predicting mathematics teachers' attitude and only education was significantly contributing to the equation for predicting mathematics teachers' attitude in teaching mathematics.
\end{abstract}

Keywords: Attitude, Confidence, Anxiety, Motivation, Success, Teaching, Mathematics

\section{INTRODUCTION}

The attitude of teachers towards teaching profession is very important for the teachers' performance and their students. Hussain, Ali, Khan, Ramzan, Qadeer (2011) found that majority of the secondary school teachers in Pakistan do not have positive attitude towards the profession. It is very critical situation for the education system, since secondary education is an important sub-sector of the entire education system and it provides the middle level manpower for the economy and on the other; it acts as a feeder for the higher level of education. Below are some of the literatures on anxiety, motivation, success and confidence of teaching mathematics that affect the attitude of teaching mathematics.

Anxiety in teaching mathematics is one of the factors that affect the attitude in teaching mathematics. Levine (1993) stated that there was a significant decrease in anxiety of teaching mathematics from the initial stage of mathematics teaching to the final stage of 
mathematics teaching. Ameen, Guffey, and Jackson (2002) reported that teaching anxiety was affected by teaching experience, age and rank. Although Ameen et al. claimed that the factors not affecting the intensity of the teaching anxiety were sex and ethnicity, in another study, Fish and Fraser (2001) found that among the university professors surveyed about teaching anxiety, sex was a factor and concluded that female faculty had more teaching anxiety than males. Furthermore, Peker and Halat (2008) found that sex was not a factor among the pre-service elementary school teachers' mathematics teaching anxiety.

Motivation and success in teaching mathematics play important roles affecting the attitude of teaching mathematics. Motivation to teach refers to one's feelings about the teaching profession. Gangoli cited in Igwe (2002) stipulates that for teaching and learning of science to be interesting, there has to be motivation on the part of both the teacher and the learner so as to enhance positive attitude and subsequently maximum academic achievement. Specifically, the attitude developed toward a profession is the most important determinant of achievement of the individual in that profession (Gürbüz and Kışoğlu, 2007). If teachers have positive attitudes toward teaching profession, this will positively influence their professional lives. Concerning success in the teaching mathematics, Akkaya (2009) determined that the female pre-service teachers who are in Turkish Education Department are more successful than male pre-service teachers with respect to their academic success.

Attitude of teachers have influenced by sex (Çapri and Çelikkaleli, 2008; Akkaya, 2009; Hussain et al., 2011) and found that female teachers have more positive attitude towards teaching profession as compared to male teachers. This may be the result of the stereotyping belief that "teaching is a feminine job". Female teachers might feel the job appropriate for them. This result is concordant with the study made by the Dodeen et el (2003), in which it was reported that female teachers have more positive attitude towards the profession as compared to the female teachers. However some researches indicated that sex was not, Çapa and Çil (2000) showed that sex was not affected on the pre-service teachers' attitude towards teaching profession, but in the sub dimension of loving profession and respect to profession, females have more positive attitude than males. On the other hand, in the sub dimension of confidence, males are more confident than females. Simşek (2005) also investigated the attitudes of pre-service teachers and found that no statistically significant difference was found in terms of sex.

Flores (2001) explored from the newly graduated teachers that what affects their attitude towards teaching profession. They indicated that social and political control existing over teachers and the profession, in addition to the economic problem. She also reported that the workplace also plays a crucial role in shaping teachers' attitudes towards teaching, especially behavior of principal, and the nature of the communication with in the school. Researchers agreed that a well qualified teacher should have positive attitudes and beliefs toward mathematics and teaching profession in order to have positive effect on their students' learning (Haser, 2006).

According to the Professional Standards for Teaching Mathematics by NCTM (1991), teachers are influenced by the teaching experience. In other words, teachers' own experiences had a profound impact on their knowledge, beliefs, and attitudes towards mathematics.

In the Ethiopian context, Ethiopian First National Learning Assessment of Grades 10 and 12 students (2010) indicated that the mean score for grade 10 students in mathematics $(34.7 \%)$ was the second from the least; and only $14.7 \%$ of grade 10 students scored $50 \%$ and above (pass mark) in mathematics that is $85.3 \%$ of the students failed in mathematics. For grade 10, boys achieved (37.4\%) significantly higher mean scores than girls (30.9\%). Similarly, the mean score for grade 12 students in mathematics was $54.3 \%$; and only $57.7 \%$ of grade 12 students scored $50 \%$ and above (pass mark) in mathematics that is $42.3 \%$ of the students failed in mathematics. For grade 12, boys achieved (56.1\%) significantly higher mean scores than girls (47.6\%). The students' academic achievement is associated with teachers' attitude in teaching mathematics. 
In the Ethiopian Second National Learning Assessment of Grade 8 students (2004) indicated that $54.3 \%$ of the teachers, who were asked whether or not they want to leave their jobs, said that they would like to change their jobs. Their main reasons were lack of attention and respect to the profession, absence of training and promotion, and students' disciplinary problems. These factors directly associated with teachers' attitude in teaching mathematics.

\section{Statement of the Problem}

In the Ethiopian Third National Learning Assessment of Grade 8 students (2008) indicated that students' achievement in grade 8 had related with six blocks of variables such as school structure and curriculum materials, teacher variables, school management, students home background and behavior, woreda education office instructional support and languages of instruction. School structure and curriculum materials, school management and instruction and student understanding were significantly associated with students' achievement. From the regression analysis, school structure and curriculum materials explained $20.5 \%$, teachers' attitude explained $32.5 \%$, school management as a block contributed $11.1 \%$, student background variables as independent group explained $36.6 \%$ of the variation in learners' achievement. The students' mathematics achievement is affected by the teachers' variables such as teachers' attitude.

Over the last decade or so, teachers, especially novices, have indicated serious dissatisfaction with the profession and have been leaving for alternative careers at an alarming rate (Metropolitan Life Survey of the American Teacher, 1996).

Therefore, the purpose of this study was to examine Addis Ababa secondary school mathematics teachers' attitude in teaching mathematics with respect to sex, age, education, service year and salary.

\section{Objective of the Study}

The objectives of the research were:

- To examine Addis Ababa secondary school mathematics teachers' attitude in terms of confidence, anxiety, motivation and success in teaching mathematics with respect to sex, age, education, service year and salary.

- To examine Addis Ababa secondary school mathematics teachers' components of attitude in terms of confidence, anxiety, motivation and success in teaching mathematics with respect to sex, age, education, service year and salary.

- To investigate the effect of the mathematics teachers' confidence, anxiety, motivation and success in teaching mathematics on mathematics teachers' attitude in teaching mathematics.

- To identify the most challenge areas of emphasis to bring positive change in the attitude of teaching mathematics.

\section{Research Question}

Below are the research questions that the study would answer:

1) Is there a significant difference in the attitude of Addis Ababa secondary school mathematics teachers' in teaching mathematics with respect to sex, age, education, service year and salary?

2) Is there a significant difference in the components of attitude of Addis Ababa secondary school mathematics teachers in terms of confidence, anxiety, motivation and success in teaching mathematics with respect to sex, age, education, service year and salary? 
3) Is there a significant effect of the mathematics teachers' confidence, anxiety, motivation and success in teaching mathematics on mathematics teachers' attitude in teaching mathematics

4) What are the most challenges in the attitude of Addis Ababa secondary school mathematics teachers in teaching mathematics?

\section{Significance of the Study}

The following major points could be stated as the importance of the study:

- It helps to know the level of attitude and components of attitude of secondary school mathematics teachers' in teaching mathematics,

- It is hoped to raise awareness to higher officials about the factors which could negatively affect the secondary school mathematics teachers' attitude in teaching mathematics,

- It helps for the concerned authorities to design strategies for reducing the problems of the teacher,

- It gives suggestions for further study in future.

\section{METHOD}

\section{The Subjects of the Study}

The subjects of the study were Addis Ababa secondary school mathematics teachers with respect to sex (male \& female), age (young, medium \& old), education (diploma, degree and masters), service year (low, average and high) and salary (low, average and relatively high).

\section{Sampling Method}

Since the numbers of secondary schools in Addis Ababa were large and the schools were divided into ten sub cities, the researcher selected one secondary school from each sub city by cluster sampling and all the mathematics teachers were considered as a sample.

\section{Variables}

A total of ten variables were considered in the present study. That is two dependent and nine independent variables. The dependent variables of the study were the attitude of secondary school mathematics teachers in teaching mathematics. The independent variables of the study were the components of attitude in teaching mathematics in terms of confidence, anxiety, motivation and success in teaching mathematics with respect to sex, age, education, service year and salary.

\section{Instruments of Data Collection}

In this study, questionnaire (attitude in teaching mathematics scale) and document were used for data collection.

\section{Mathematics teachers' attitude in teaching mathematics scale}

The mathematics teachers' attitude in teaching mathematics scale was used to assess the mathematics teachers' perception in teaching mathematics. The scale contains 24 items; that is, the questions were in the main title of confidence, anxiety, motivation and success in teaching mathematics. The respondents were asked to respond to each item using a five point scale such as strongly agree $=5$, agree $=4$, neutral $=3$, disagree $=2$ and 
strongly disagree $=1$ for positive questions and strongly agree $=1$, agree $=2$, neutral $=3$, disagree $=4$ and strongly disagree $=5$ for negative questions.

\section{Validity and Reliability of the Instruments}

The mathematics teachers' attitude scale was reviewed based on the comments of professionals for the face and content validity. A pilot study was conducted to determine the validity and reliability of the mathematics teachers' attitude scale. Two secondary schools were chosen by simple random sampling from secondary schools of Addis Ababa administrative region for the pilot study. From the pilot study construct validity were established by calculating correlations between the mathematics teachers' attitude and independent variables confidence, anxiety, motivation and success in teaching mathematics. Therefore, all the independent variables are correlated with the dependent variables and the correlations were significant at 0.05 level of significance. The alpha coefficient of Cronbach yielded 0.771 for attitude in teaching mathematics, 0.714 for confidence in teaching mathematics, 0.780 for anxiety of teaching mathematics, 0.781 for motivation in teaching mathematics, 0.84 for success in teaching mathematics. Cronbach Alpha coefficients of reliability for the variables attitude, confidence, anxiety, motivation and success in teaching mathematics indicated that they have high internal-consistency reliability.

\section{Data Analysis Techniques}

The data analysis techniques for this study were independent t-test, ANOVA, tukey test and regression analysis.

\section{FINDINGS AND DISCUSSION}

Table 1 is the average and standard deviation for the response of the mathematics teachers in the attitude of teaching mathematics.

Table 1. The descriptive statistics for mathematics teachers' attitude of teaching mathematics

\begin{tabular}{lrcc}
\hline Variable & $\mathbf{N}$ & Mean & SD \\
Attitude & 148 & 3.9115 & .34384 \\
\hline
\end{tabular}

The attitude of teachers towards teaching profession is very important for the teachers' performance and their students. The analysis of the data revealed that the significant number of the secondary school teachers did not possess positive attitude in teaching mathematics. It is alarming situation for our education system since secondary education is an important sub-sector of the entire education system. It provides the middle level workforce for the economy and on the other; it acts as a feeder for the higher level of education (Hussain et al., 2011). In order to answer the first two research questions, the analysis is divided in terms of sex, age, education, service year and salary.

\section{Sex}

The first step was to check whether there were significant differences or not in the attitude, confidence, anxiety, motivation and success in teaching mathematics, with respect to sex. Table 2 showed the descriptive statistics and the independent sample t-test for attitude in teaching mathematics and its components with respect to sex. 
Table 2. Descriptive statistics and the independent samples t-test for mathematics teachers' attitude in teaching mathematics and its components with respect to sex

\begin{tabular}{|c|c|c|c|c|c|c|c|}
\hline \multirow[t]{2}{*}{ Groups } & \multirow[t]{2}{*}{$\mathbf{N}$} & \multicolumn{6}{|c|}{ Attitude in Teaching Mathematics Scale } \\
\hline & & $\mathbf{M}$ & SD & SE & df & $\mathbf{t}$ & $\mathbf{p}$ \\
\hline \multicolumn{8}{|l|}{ Attitude } \\
\hline Male & 20 & 3.8970 & .33989 & .03004 & 146 & 1.304 & .194 \\
\hline Female & 128 & 4.0045 & .36328 & .08123 & & & \\
\hline \multicolumn{8}{|c|}{ Confidence } \\
\hline Male & 20 & 4.2068 & .54965 & .04858 & 146 & .270 & .788 \\
\hline Female & 128 & 4.2420 & .49275 & .11018 & & & \\
\hline \multicolumn{8}{|l|}{ Anxiety } \\
\hline Male & 20 & 3.6295 & .59616 & .05269 & 146 & 1.458 & .147 \\
\hline Female & 128 & 3.8420 & .66902 & .14960 & & & \\
\hline \multicolumn{8}{|c|}{ Motivation } \\
\hline Male & 20 & 4.5600 & .51426 & .04545 & 146 & 1.504 & .135 \\
\hline Female & 128 & 4.3797 & .37613 & .08411 & & & \\
\hline \multicolumn{8}{|l|}{ Success } \\
\hline Male & 20 & 3.4948 & .53307 & .04712 & 146 & .037 & .970 \\
\hline Female & 128 & 3.4995 & .49128 & .10985 & & & \\
\hline
\end{tabular}

From table 2, since all the p values were greater than 0.05 then there were no significant differences between males and females in the variables attitude, confidence, anxiety, motivation and success in teaching mathematics. This finding seems to be aligned with the results of various studies conducted by Çapa and Çil (2000) and Şimşek (2005) showed that no statistically significant difference in the attitude of teaching mathematics in terms of sex. However, it did not align with the results of the works by Çapri and Çelikkaleli (2008). Akkaya (2009) and Hussain et al. (2011) showed that females have a more positive attitude toward the teaching profession than males. On the other hand, in the sub dimension of confidence, there was no significant difference in terms of sex. The result supported by the finding of Şimssek (2005) showed that no statistically significant difference in terms of sex. Similarly, the above result indicated that there is no significant difference in anxiety between females and males in the teaching of mathematics. The finding of the study aligned with the findings of the research by Peker and Halat (2008) showed that sex was not a factor among the teachers' mathematics teaching anxiety, but didn't aligned with the finding of Fish and Fraser (2001) indicating that female teachers have more teaching anxiety than males. Finally the result of the study indicated that there was no significant difference in success of teaching mathematics with respect to sex. But the result did not supported by the findings of Akkaya (2009) determined that the female pre-service teachers who are in Turkish Education Department are more successful than male pre-service teachers with respect to their teaching profession.

\section{Age}

The second step was to check whether there were significant differences or not in the attitude, confidence, anxiety, motivation and success in teaching mathematics with respect to age. Table 3 showed the descriptive statistics and the F-test for attitude and its components with respect to age. 
Table 3. Descriptive statistics and the independent samples t-test for mathematics teachers' attitude and its components with respect to age

\begin{tabular}{|c|c|c|c|c|c|c|c|}
\hline \multirow[t]{2}{*}{ Groups } & \multirow[t]{2}{*}{$\mathbf{N}$} & \multicolumn{6}{|c|}{ Attitude in Teaching Mathematics Scale } \\
\hline & & $\mathbf{M}$ & SD & SE & df & $\mathbf{F}$ & $\mathrm{p}$ \\
\hline \multicolumn{8}{|l|}{ Attitude } \\
\hline Young & 80 & 3.8824 & .38234 & .04275 & 2 & 1.205 & .303 \\
\hline Medium & 45 & 3.9778 & .29167 & .04348 & 145 & & \\
\hline Old & 23 & 3.8830 & .28627 & .05969 & 147 & & \\
\hline \multicolumn{8}{|c|}{ Confidence } \\
\hline Young & 80 & 4.1709 & .58925 & .06588 & 2 & .812 & .446 \\
\hline Medium & 45 & 4.2218 & .50847 & .07580 & 145 & & \\
\hline Old & 23 & 4.3330 & .41128 & .08576 & 147 & & \\
\hline \multicolumn{8}{|l|}{ Anxiety } \\
\hline Young & 80 & 3.6715 & .71931 & .08042 & 2 & .648 & .525 \\
\hline Medium & 45 & 3.7009 & .43365 & .06464 & 145 & & \\
\hline Old & 23 & 3.5287 & .46662 & .09730 & 147 & & \\
\hline \multicolumn{8}{|l|}{ Motivation } \\
\hline Young & 80 & 4.4375 & .54758 & .06122 & 2 & .647 & .525 \\
\hline Medium & 45 & 4.3333 & .37899 & 05650 & 145 & & \\
\hline Old & 23 & 4.4261 & .54374 & .11338 & 147 & & \\
\hline \multicolumn{8}{|l|}{ Success } \\
\hline Young & 80 & 3.3749 & .50165 & .05609 & 2 & 9.034 & .000 \\
\hline Medium & 45 & 3.7591 & .47477 & .07077 & 145 & & \\
\hline Old & 23 & 3.3987 & .53808 & .11220 & 147 & & \\
\hline
\end{tabular}

From table 3 of $\mathrm{F}$ ratios of $\mathrm{p}$ values of the age component it can be concluded that there was only a significant difference in the three age groups of mathematics teachers in success of teaching mathematics. For the other variables such as attitude, confidence, anxiety and motivation in teaching mathematics, there were no significant difference between the three age groups. However, this finding seems to be not aligned with the result of the study conducted by Ameen, Guffey, and Jackson (2002) reported that accounting educators' intensity of teaching anxiety was affected by age.

Since the mathematics teachers had a significant difference in success of teaching mathematics with respect to the age level, then the next question was which of the age levels made more significant difference. To find these paired comparisons Tukey HSD test was used. The Tukey HSD test for the paired age levels for success in teaching mathematics is given by table 4 .

Table 4. Tukey test for the paired age levels of mathematics teachers in success of teaching mathematics

\begin{tabular}{ccccc}
\hline (I) Age level & (J) Age level & Mean Difference (I-J) & Std. Error & P \\
Young & Medium & $-.38424\left(^{*}\right)$ & .09306 & .000 \\
& Old & -.02382 & .11816 & .978 \\
Medium & Old & $.36042\left(^{*}\right)$ & .12802 & .015 \\
\hline
\end{tabular}

* The mean difference is significant at the .05 level.

From table 4 of age variable, the medium age of mathematics teachers made more significant difference with the younger and older age of the mathematics teachers in success of teaching mathematics. But ther is no significant difference between the younger and older age of the mathematics teachers in success of teaching mathematics. The medium age teachers $(M=3.7591)$ were significantly high successful in teaching mathematics than the younger teachers $(M=3.3749)$ and older teachers $(M=3.3987)$. In the first years of teaching, the teachers will come less experienced in subject knowledge, method of teaching, method of assessment, classroom management, lesson note 
preparation, etc. However, the medium age teachers are experiencing the above conditions and become successful, for the older teachers other factors may affect the success of teaching mathematics.

\section{Education}

The third step was to check whether there were significant differences or not in the attitude, confidence, anxiety, motivation and success in teaching mathematics with respect to education. Table 5 showed the descriptive statistics and the F-test for attitude in teaching mathematics and its components with respect to education.

Table 5. Descriptive statistics and the independent samples t-test for mathematics teachers' attitude and its components with respect to education

\begin{tabular}{|c|c|c|c|c|c|c|c|}
\hline \multirow[t]{2}{*}{ Groups } & \multirow[t]{2}{*}{$\mathbf{N}$} & \multicolumn{6}{|c|}{ Attitude in Teaching Mathematics Scale } \\
\hline & & $\mathbf{M}$ & SD & SE & df & F & $\mathrm{p}$ \\
\hline \multicolumn{8}{|l|}{ Attitude } \\
\hline Diploma & 16 & 3.6281 & .29663 & .07416 & 2 & 6.787 & .002 \\
\hline Degree & 125 & 3.9414 & .33809 & .03024 & 145 & & \\
\hline Master & 7 & 4.0257 & .25748 & .09732 & 147 & & \\
\hline \multicolumn{8}{|c|}{ Confidence } \\
\hline Diploma & 16 & 3.8338 & .50889 & .12722 & 2 & 4.727 & .010 \\
\hline Degree & 125 & 4.2518 & .53686 & .04802 & 145 & & \\
\hline Master & 7 & 4.3557 & .35326 & .13352 & 147 & & \\
\hline \multicolumn{8}{|l|}{ Anxiety } \\
\hline Diploma & 16 & 3.1513 & .73020 & .18255 & 2 & 7.010 & .001 \\
\hline Degree & 125 & 3.7108 & .57325 & .05127 & 145 & & \\
\hline Master & 7 & 3.8786 & .38238 & .14453 & 147 & & \\
\hline \multicolumn{8}{|c|}{ Motivation } \\
\hline Diploma & 16 & 4.3375 & .50448 & .12612 & 2 & .652 & .522 \\
\hline Degree & 125 & 4.4224 & .50687 & .04534 & 145 & & \\
\hline Master & 7 & 4.2286 & .37289 & .14094 & 147 & & \\
\hline \multicolumn{8}{|l|}{ Success } \\
\hline Diploma & 16 & 3.3863 & .44153 & .11038 & 2 & .824 & .441 \\
\hline Degree & 125 & 3.4985 & .53748 & .04807 & 145 & & \\
\hline Master & 7 & 3.6900 & .49528 & .18720 & 147 & & \\
\hline
\end{tabular}


From table 5 of $\mathrm{F}$ ratios of $\mathrm{p}$ values it can be concluded that there were significant differences in the three educational levels of mathematics teachers in attitude, confidence and anxiety of teaching mathematics. For the other two variables such as motivation and success in teaching mathematics, there were no significant differences between the three educational levels. This finding in terms of attitude in teaching mathematics and education seems to be aligned with the results of the study conducted by Haser (2006), showed that a well qualified teacher have positive attitudes and beliefs toward mathematics and teaching profession.

Since the mathematics teachers had significant differences in attitude, confidence and anxiety of teaching mathematics with respect to the educational level, then the next question was which of the educational levels made more significant differences. To find these paired comparisons Tukey HSD test were used. The Tukey HSD test for the paired educational levels for attitude, confidence and anxiety in teaching mathematics is given by table 6.

Table 6. Tukey HSD test for the paired educational levels of mathematics teachers in attitude, confidence and anxiety of teaching mathematics

\begin{tabular}{cccccc}
\hline Variable & (I) Education & (J) Education & Mean Difference (I-J) & Std. Error & P \\
Attitude & Diploma & Degree & $-.31324\left(^{*}\right)$ & .08790 & .001 \\
& & Master & $-.39759\left(^{*}\right)$ & .15002 & .024 \\
Confidence & Degree & Master & -.08435 & .12858 & .789 \\
& Diploma & Degree & $-.41809\left(^{*}\right)$ & .14010 & .009 \\
& & Master & $-.52196\left(^{*}\right)$ & .23912 & .038 \\
Confidence & Degree & Master & .10387 & .20495 & .868 \\
& Diploma & Degree & $-.55955\left(^{*}\right)$ & .15533 & .001 \\
& & Master & $-.72732\left(^{*}\right)$ & .26510 & .019 \\
& Degree & Master & -.16777 & .22722 & .741 \\
\hline
\end{tabular}

* The mean difference is significant at the .05 level.

From table 6 of educational level variable, the mathematics teachers of diploma level made more significant difference with the mathematics teachers of degree and masters levels in attitude, confidence and anxiety in teaching mathematics. But there is no significant difference between the mathematics teachers of degree and masters levels in attitude, confidence and anxiety in teaching mathematics.

Diploma teachers $(M=3.6281$ for attitude, $M=3.8338$ for confidence and $M=3.1513$ for anxiety) were significantly less in attitude, confidence and anxiety in teaching mathematics than the degree teachers $(\mathrm{M}=3.9414$ for attitude, $\mathrm{M}=4.2518$ for confidence and $\mathrm{M}=$ 3.7108 for anxiety) and master teachers $(M=4.0257$ for attitude, $M=4.3557$ for confidence and $\mathrm{M}=3.8786$ for anxiety). This may be explained by the subject knowledge of the teachers. The diploma teachers assumes himself had less mathematics knowledge and this affected the attitude and confidence in teaching mathematics and become more frustrated in the teaching mathematics than the degree and master teachers. 


\section{Service Year}

The fourth step is to check whether there were significant differences or not in the attitude, confidence, anxiety, motivation and success in teaching mathematics with respect to service year. Table 7 showed the descriptive statistics and the F-test for attitude teaching mathematics and its components with respect to service year.

Table 7. Descriptive statistics and the independent samples t-test for mathematics teachers' attitude and its components with respect to service year

\begin{tabular}{|c|c|c|c|c|c|c|c|}
\hline \multirow[t]{2}{*}{ Groups } & \multirow[t]{2}{*}{$\mathbf{N}$} & \multicolumn{6}{|c|}{ Attitude in Teaching Mathematics Scale } \\
\hline & & $\mathbf{M}$ & SD & SE & df & $\mathbf{F}$ & Sig. \\
\hline \multicolumn{8}{|l|}{ Attitude } \\
\hline Low & 75 & 3.8863 & .39693 & .07416 & 2 & .452 & .637 \\
\hline Average & 40 & 3.9485 & .31173 & .03024 & 145 & & \\
\hline High & 33 & 3.9239 & .23863 & .09732 & 147 & & \\
\hline \multicolumn{8}{|c|}{ Confidence } \\
\hline Low & 75 & 4.1576 & .57887 & .06684 & 2 & .781 & .460 \\
\hline Average & 40 & 4.2538 & .56494 & .08932 & 145 & & \\
\hline High & 33 & 4.2830 & .40706 & .07086 & 147 & & \\
\hline \multicolumn{8}{|l|}{ Anxiety } \\
\hline Low & 75 & 3.6784 & .70887 & .08185 & 2 & .091 & .913 \\
\hline Average & 40 & 3.6460 & .45738 & .07232 & 145 & & \\
\hline High & 33 & 3.6273 & .53061 & .09237 & 147 & & \\
\hline \multicolumn{8}{|c|}{ Motivation } \\
\hline Low & 75 & 4.4133 & .56024 & .06469 & 2 & .456 & .635 \\
\hline Average & 40 & 4.3450 & .42484 & .06717 & 145 & & \\
\hline High & 33 & 4.4545 & .44518 & .07750 & 147 & & \\
\hline \multicolumn{8}{|l|}{ Success } \\
\hline Low & 75 & 3.4153 & .50352 & .05814 & 2 & 2.984 & .054 \\
\hline Average & 40 & 3.6623 & .54630 & .08638 & 145 & & \\
\hline High & 33 & 3.4752 & .52038 & .09059 & 147 & & \\
\hline
\end{tabular}

From table 7 of $\mathrm{F}$ ratios of $\mathrm{p}$ values it can be concluded that there were no significant differences in the three service year groups of mathematics teachers in attitude, confidence, anxiety, motivation and success of teaching mathematics. However, this finding in terms of anxiety in teaching mathematics and service year seems to be not aligned with the results 
of the studies conducted by Ameen, Guffey and Jackson (2002); and NCTM (1991) indicated that accounting educators' intensity of teaching anxiety was affected by teaching experience; Levine (1993) stated that there was a significant decrease in anxiety in teaching mathematics from the initial to the final meeting of the mathematics methods.

\section{Salary}

The fifth step was to check whether there were significant differences or not in the attitude, confidence, anxiety, motivation and success in teaching mathematics with respect to salary. Table 8 showed the descriptive statistics and the F-test for attitude in teaching mathematics and its components with respect to salary.

Table 8. Descriptive statistics and the independent samples t-test for mathematics teachers' attitude and its components with respect to salary

\begin{tabular}{|c|c|c|c|c|c|c|c|}
\hline \multirow[t]{2}{*}{ Groups } & \multirow[t]{2}{*}{$\mathbf{N}$} & \multicolumn{6}{|c|}{ Attitude in Teaching Mathematics Scale } \\
\hline & & $\mathbf{M}$ & SD & SE & df & $\mathbf{F}$ & Sig. \\
\hline \multicolumn{8}{|l|}{ Attitude } \\
\hline Low & 22 & 3.7018 & .49071 & .10462 & 2 & 5.150 & .007 \\
\hline Average & 94 & 3.9414 & .30883 & .03185 & 145 & & \\
\hline Relatively high & 32 & 3.9678 & .27235 & .04814 & 147 & & \\
\hline \multicolumn{8}{|l|}{ Confidence } \\
\hline Low & 22 & 3.9773 & .58851 & .12547 & 2 & 2.753 & .067 \\
\hline Average & 94 & 4.2320 & .55100 & .05683 & 145 & & \\
\hline Relatively high & 32 & 4.3125 & .43711 & .07727 & 147 & & \\
\hline \multicolumn{8}{|l|}{ Anxiety } \\
\hline Low & 22 & 3.2595 & .80373 & .17136 & 2 & 6.057 & .003 \\
\hline Average & 94 & 3.7433 & .55582 & .05733 & 145 & & \\
\hline Relatively high & 32 & 3.6825 & .50572 & .08940 & 147 & & \\
\hline \multicolumn{8}{|l|}{ Motivation } \\
\hline Low & 22 & 4.4000 & .71448 & .15233 & 2 & .091 & .913 \\
\hline Average & 94 & 4.3936 & .45004 & .04642 & 145 & & \\
\hline Relatively high & 32 & 4.4375 & .48310 & .08540 & 147 & & \\
\hline \multicolumn{8}{|l|}{ Success } \\
\hline Low & 22 & 3.3564 & .66143 & .14102 & 2 & 1.050 & .353 \\
\hline Average & 94 & 3.5049 & .47438 & .04893 & 145 & & \\
\hline Relatively high & 32 & 3.5631 & .56734 & .10029 & 147 & & \\
\hline
\end{tabular}


From table 8 of $F$ ratios of $p$ values it can be concluded that there were significant differences in the three salary levels of mathematics teachers in attitude and anxiety of teaching mathematics, but there are no significant differences in the three salary levels of mathematics teachers in confidence, motivation and success of teaching mathematics.

Since the mathematics teachers had significant differences in attitude and anxiety of teaching mathematics with respect to the salary level, then the next question was which of the salary levels made more significant differences. To find these paired comparisons Tukey HSD test was used. The Tukey HSD test for the paired salary levels for attitude and anxiety in teaching mathematics is given by table 9 .

Table 9. Tukey HSD test for the paired salary levels of mathematics teachers in attitude and anxiety of teaching mathematics

\begin{tabular}{|c|c|c|c|c|c|}
\hline Variable & (I) Education & (J) Education & Mean Difference (I-J) & Std. Error & $\mathrm{p}$ \\
\hline \multirow[t]{3}{*}{ Attitude } & Low & Average & $-.23956\left(^{*}\right)$ & .07923 & .008 \\
\hline & & Relatively high & $-.26599(*)$ & .09265 & .013 \\
\hline & Average & Relatively high & -.02643 & .06847 & .921 \\
\hline \multirow[t]{3}{*}{ Anxiety } & Low & Average & $-.48375(*)$ & 13939 & .002 \\
\hline & & Relatively high & $-.42295(*)$ & .16300 & .028 \\
\hline & Average & Relatively high & .06080 & 12045 & .869 \\
\hline
\end{tabular}

* The mean difference is significant at the .05 level.

From table 9 of salary level variable, the mathematics teachers who have low salary made more significant differences with the teachers who have relatively high and average salary in attitude and anxiety in teaching mathematics. But there is no significant difference between the teachers who have average salary and relatively high salary in attitude and anxiety in teaching mathematics.

Low salary teachers $(M=3.7018$ for attitude and $M=3.2595$ for anxiety $)$ were significantly less in attitude and anxiety in teaching mathematics than the average salary teachers $(M=3.9414$ for attitude and $M=3.7433$ for anxiety) and relatively high salary teachers $(\mathrm{M}=3.9678$ for attitude and $\mathrm{M}=3.6825$ for anxiety). This may be explained as even though the difference of the salary amount is small amount made a significant difference in the attitude and anxiety of teaching mathematics.

\section{Mathematics Teachers' Attitude in Teaching Mathematics}

Table 10 is the response of the mathematics teachers in terms the challenge areas selected from confidence, anxiety, motivation and success in the order of challenges that contribute in teaching mathematics. 
Table 10. The percent of the challenge areas for the different attitude variables

\begin{tabular}{|c|c|c|c|c|c|c|c|c|c|}
\hline \multirow{3}{*}{ Variable } & \multicolumn{8}{|c|}{ The most critical area selected } & \multirow{3}{*}{ Weighted mean } \\
\hline & \multicolumn{2}{|c|}{ First } & \multicolumn{2}{|c|}{ Second } & \multicolumn{2}{|c|}{ Third } & \multicolumn{2}{|c|}{ Fourth } & \\
\hline & f & $\%$ & f & $\%$ & $\mathbf{F}$ & $\%$ & f & $\%$ & \\
\hline Confidence & 40 & $27.03 \%$ & 61 & $41.22 \%$ & 27 & $18.24 \%$ & 20 & $13.51 \%$ & 2.18 \\
\hline Anxiety & 40 & $27.03 \%$ & 14 & $9.46 \%$ & 40 & $27.03 \%$ & 54 & $36.5 \%$ & 2.73 \\
\hline Motivation & 54 & $36.5 \%$ & 54 & $36.5 \%$ & 33 & $22.3 \%$ & 7 & $4.7 \%$ & 1.95 \\
\hline Success & 14 & $9.46 \%$ & 20 & $13.51 \%$ & 47 & $31.76 \%$ & 67 & $45.27 \%$ & 3.40 \\
\hline
\end{tabular}

From the above table, the most challenge area that affected the mathematics teachers' attitude in teaching mathematics was motivation (first selection (36.5\%), second selection $(36.5 \%)$, third selection $(22.3 \%)$, and fourth selection $(4.7 \%))$ and the least challenge area that affected the mathematics teachers' attitude in teaching mathematics was success (first selection (9.46\%), second selection (13.51\%), third selection (31.76\%), and fourth selection $(45.27 \%))$. The reasons for decreasing the attitude, confidence, motivation, anxiety and success in teaching mathematics responded by the mathematics teachers were small amount of salary, shortage of part-time job, the part-time payment rate of the school is very small, students' attitude in learning mathematics are very low, cheating of students in mathematics examinations, the performance of the students is very low, the students' behavior is not good, the instrument of the evaluation is not appropriate, the evaluation procedure is not good, problems in the recognition of teachers job by the students, parents and government, shortage of scholarship for further study, absence of health insurance, there is no comfortable work conditions, the teaching load in mathematics is very high, less opportunities of getting transfer from one region to an other region and from one school to an other school, there is no good management system, English language proficiency is low, giving basic knowledge for lower grade students is difficult, difficulty of evaluating students' ability, properly in providing mathematics teaching aids is difficult, applying the appropriate methods of teaching are not good, etc.

Having fewer attitudes of mathematics teachers in teaching mathematics, it is difficult to increase the achievement of students in mathematics, since there were a large number of students failed in mathematics. According to the Ethiopian First National Learning Assessment of Grade 10 and 12 Students, 2010 stated that $85.3 \%$ of grade 10 students and $42.3 \%$ of grade 12 students failed in mathematics test.

Table 11 and 12 showed the relationships between each of the components of attitude such as confidence, motivation, anxiety and success in teaching mathematics on attitude in teaching mathematics.

Table 11. ANOVA table that shows collective impact of confidence, motivation, anxiety and success in teaching mathematics on attitude in teaching mathematics

\begin{tabular}{cccccc} 
ANOVA Table & Sum of Squares & df & Mean Square & F & p \\
Regression & 17.376 & 4 & 4.344 & $196059.64^{*}$ & .000 \\
Residual & .003 & 143 & .000 & & \\
Total & 17.379 & 147 & & & \\
\hline
\end{tabular}


In the ANOVA table $11, \mathrm{~F}$ value indicated that the multiple correlations $\mathrm{R}$ were significant for mathematics teachers' attitude in teaching mathematics that is the contribution of all variables confidence, motivation, anxiety and success in teaching mathematics $(C, M, A$ and $S$ respectively) collectively significantly affected the mathematics teachers' attitude in teaching mathematics.

Table 12. t-table that shows individual impact of confidence, motivation, anxiety and success in teaching mathematics on attitude in teaching mathematics

\begin{tabular}{ccccccc}
\hline Variable & $\mathbf{r}$ & $\mathbf{B}$ & Std. Error & Beta & $\mathbf{t}$ & $\mathbf{p}$ \\
Confidence & $.727^{*}$ & .250 & .001 & .393 & $311.822^{*}$ & .000 \\
Anxiety & $.663^{*}$ & .292 & .001 & .516 & $439.713^{*}$ & .000 \\
Motivation & $.515^{*}$ & .209 & .001 & .304 & $257.857^{*}$ & .000 \\
Success & $.563^{*}$ & .250 & .001 & .382 & $323.111^{*}$ & .000 \\
\hline
\end{tabular}

In table 12, all of the independent variables were significantly correlated with attitude in teaching mathematics. Confidence in teaching mathematics is highly correlated with attitude in teaching mathematics. The $t$ values indicated that the contribution of confidence, anxiety, motivation and success in teaching mathematics were significantly affected the mathematics teachers' attitude in teaching mathematics.

Next beta was used in order to compare the effect or contribution of each of the components on mathematics teachers' attitude in teaching mathematics. The percent of effect or contribution of each component mathematics teachers' confidence, anxiety, motivation and success in teaching mathematics ( $\mathrm{C}, \mathrm{A}, \mathrm{M}$ and $\mathrm{S}$ respectively) on the mathematics teachers' attitude in teaching mathematics $(X)$ can be found by $\left(R^{2}=\beta_{C} r_{X C}+\right.$ $\left.\beta_{\mathrm{A}} \mathrm{r}_{\mathrm{XA}}+\beta_{\mathrm{M}} \mathrm{r}_{\mathrm{XM}}+\beta_{\mathrm{S}} \mathrm{r}_{\mathrm{XS}}\right) \times 100 \%$. That is,

$100 \% \approx 28.57 \%+34.21 \%+15.66 \%+21.51 \%$

Therefore, the contribution of mathematics teachers' confidence in teaching mathematics enhanced the mathematics teachers' attitude in teaching mathematics by $28.57 \%$, mathematics teachers' anxiety in teaching mathematics enhanced the mathematics teachers' attitude in teaching mathematics by $34.21 \%$, mathematics teachers' motivation in teaching mathematics enhanced the mathematics teachers' attitude in teaching mathematics by $15.66 \%$ and mathematics teachers' success of teaching mathematics enhanced the mathematics teachers' attitude in teaching mathematics by $21.51 \%$.

\section{CONCLUSIONS AND IMPLICATIONS}

The purpose of this study was to examine Addis Ababa secondary school mathematics teachers' attitude in teaching mathematics with respect to sex, training, age, education, service year and salary level. From the result and discussion of the study the following findings were obtained:

The analysis of the data revealed that the significant number of the secondary school mathematics teachers did not possess positive attitude in teaching mathematics. Secondary education is an important sub-sector of the entire education system. It provides the middle level workforce for the economy and on the other it acts as a feeder for the higher level of education.

There were no significant differences in the variables attitude, confidence, anxiety, motivation and success in teaching mathematics with respect to sex.

Although the attitude, confidence, anxiety and motivation of the mathematics teachers in teaching mathematics showed no statistically significant difference in terms of age, the medium age of mathematics teachers found to have significantly most successful in teaching mathematics than younger and older mathematics teachers.

Although the motivation and success of the mathematics teachers in teaching mathematics showed no statistically significant difference in terms of education, the master 
mathematics teachers found to have significantly the highest and the diploma mathematics teachers found to have the least attitude, confidence and anxiety of teaching mathematics.

There were no significant differences in the three service year groups of mathematics teachers in attitude, confidence, anxiety, motivation and success of teaching mathematics.

Although the confidence, motivation and success of the mathematics teachers in teaching mathematics showed no statistically significant differences in terms of salary, the relatively high salary of the mathematics teachers found to have significantly the highest attitude in teaching mathematics, but the low salary teachers have the least attitude in teaching mathematics. Similarly, the average salary of the mathematics teachers found to have significantly the highest anxiety in teaching mathematics but the low salary of the mathematics teachers found to have significantly the least in anxiety of teaching mathematics.

The most challenge area that affects the mathematics teachers' attitude in teaching mathematics was motivation of teaching mathematics and the least challenge area was success of teaching mathematics.

The contribution of all variables mathematics teachers' confidence, motivation, anxiety and success in teaching mathematics collectively significantly affected the mathematics teachers' attitude in teaching mathematics. Similarly, the contribution of the variables such as confidence, anxiety, motivation and success in teaching mathematics were significantly affected the mathematics teachers' attitude in teaching mathematics.

Some of the recommendations given by the researcher were as follows: to increase the attitude, enhance the confidence, improve the motivation, reduce the anxiety and increase the success of the mathematics teachers in teaching mathematics the concerned authorities give short term training on the English language proficiency, method of teaching and evaluation of students' work to the mathematics teachers; give higher training in mathematics; provide modern mathematics teaching aids; increase the salary; improve students' attitude in learning mathematics, the discipline of the students, the performance of the students; revise the instrument of the evaluation of the promotion; give recognition for the teachers job; give other benefits like health insurance, further training, opportunity to transfer; reduce the teaching load, provide sufficient instructional materials; reduce the class size, etc.

\section{REFERENCES}

Akkaya N (2009). Teachers' Attitudes Towards Teaching Profession An Investigation of Some Variables. Dokuz Eylul University, Buca Faculty of Educ. J., 25: 35-42.

Ameen, E.C., Guffey, D.M., \& Jackson, C. (2002). Evidence of teaching anxiety among accounting educators. Journal of Education for Business, 78(1), 16-22.

Campbell, A., Converse, P., \& Rodgers, W. (1976). The quality of American life. New York: Sage.

Capa Y, Cil N (2000). Teachers' Attitudes Towards Teaching Profession An Investigation of the different variables. Hacettepe University J. Educ., 18: 69-73.

Capri B, Celikkaleli Ö (2008). Teachers' Attitudes toward Teaching and Professional Competence Beliefs Gender, the Program and Investigation of Faculties, Inonu
University Faculty of Education J., 9(15): 33-53

DeVoe, J., Peter, K., Kaufman, P., Miller, A., Noonan, M., Snyder, T., et al. (2004). Indicators of school crime and safety, 2004. Washington, DC: National Center for Educational Statistics.

Dodeen, H.A., Ibrahim, A. A., Emad, M, (2003). Attitude of Pre Service Teachers towards Persons with Disability: Prediction for the Success of Inclusion. College Student Journal, Vol. 37., (4), p.515

Fish, T.A. \& Fraser, I.H. (2001). Exposing the iceberg of teaching anxiety: a survey of faculty at three New Brunswick Universities. Electronic Journal of the American Association of Behavioral and Social Sciences, 4, Available at http://www.aabss.org/journal2001/Fish20 
01.jmm.html, Retrieved 8 April 2008 (last accessed 8 April 2008).

Gürbüz, H., \& Kışoğlu, M. (2007). Attitudes of the science and art faculty students and education faculty students attend the nonthesis graduated education program toward teaching profession (Atatürk university sample). Erzincan Eğitim Fakültesi Dergisi, 9(2), 71-83.

Hussain S, Ali R, Khan MS, Ramzan M, Qadeer MZ (2011). Attitude of Secondary School Teachers Towards Teaching Profession. Int. J. Acad. Res., 3(1): 985-990.

Igwe, R.O. (2002). Teacher Empowerment: Relevance for Quality Teaching and Learning. African Journal of Curriculum and Instruction. Vol.1, No.1 pp.113 - 122.

Levine, G. (1993). Prior mathematics history, anticipated mathematics teaching style, and anxiety for teaching mathematics among preservice elementary school teachers. Paper presented at the Annual Meeting of the International Group for Psychology of Mathematics Education, North American Chapter, ERIC Document Reproduction Service No. ED373972.

Metropolitan Life Survey of the American Teacher (1996). The American Teacher 1984 -1995; Old Problems, new challenges. New York: Louis Harris and Associates, Inc.

National Council of Teachers of Mathematics (1991). Professional standards for teaching mathematics. Reston, VA: National Council of Teachers of Mathematics, Ine.
National Agency for Examination (2004). Ethiopian Second National Learning Assessment of Grades 4 and 8 students, Addis Ababa, Ethiopia

National Agency for Examination (2008). Ethiopian Third National Learning Assessment of Grades 4 and 8 students, Addis Ababa, Ethiopia

National Agency for Examination (2010). Ethiopian First National Learning Assessment of Grades 10 and 12 students, Addis Ababa, Ethiopia

Peker, M. \& Halat, E. (2008). The pre-service teachers' mathematics teaching anxiety and gender. Paper presented in The European Conference on Educational Research (12 September, Gothenburg, Sweden).

Simsek H (2005). Secondary School Teacher Education Program Continuing MA Students' Attitudes Towards Teaching Profession. Yuzuncu Yil University Faculty of Educ. J., 2(1): 25-50.

$\diamond \diamond \diamond$

\section{Citation Suggestions :}

APA : Atnafu, M. (2014). Secondary School Mathematics Teachers' Attitude in Teaching Mathematics. Mathematics Education, 9(1), 57-72. 